\title{
Neuroendocrine Changes in Aging and Alzheimer's Disease
}

\author{
D. F. Swaab, E. Goudsmit, H.P. H. Kremer, \\ R. Ravid, and W. Witting
}

Here in this well-concealed spot, almost to be covered with a thumbnail lies the very mainspring of primitive existence-vegetative, emotional, reproductive-on which with more or less success, man has come to superimpose a cortex of inhibitions.

- H. Cushing, 1929

(from Plum and Van Uitert, 1978)

Alterations in hypothalamic structures and functions are thought to be causal in diseases such as anorexia nervosa, depression, Cushing's disease, diabetes insipidus, Prader-Willi-syndrome, polycystic ovaries syndrome, and the malignant neuroleptic syndrome, as well as in disturbances in sleep and temperature regulation. In addition, the hypothalamus is affected in neurodegenerative diseases and might be responsible for particular symptoms, e.g., in Alzheimer's, Parkinson's and Huntington's diseases and possibly in multiple sclerosis. Moreover, this brain region is presumed to be altered in adrenogenital syndrome, by hormones given during development (e.g., diethylstibestrol (DES)), and in Turner's, Klinefelter's and Kallman's syndromes.

In spite of this impressive list, knowledge on the normal development, sexual differentiation, and aging of the human hypothalamus is hardly available. Data on how the pathophysiology of the conditions mentioned above is reflected in the morphology of the human hypothalamus are essentially nonexistent. In the present chapter, recent data on morphological alterations of several hypothalamic structures in normal aging and Alzheimer's disease are presented. The sexually dimorphic nucleus (SDN), the suprachiasmatic nucleus (SCN), the supraoptic nucleus (SON), the paraventricular nucleus (PVN), and the nucleus tuberalis lateralis (NTL) were selected in order to illustrate the variety in changes occurring in brain-endocrine interactions in the human hypotha- 
lamus during these conditions. Alzheimer's disease can in many respects be considered as an advanced, accelerated form of aging.

\section{Sexually Dimorphic Nucleus}

The sexually dimorphic nucleus of the preoptic area (SDN) was first described in the rat brain by Gorski et al. (1978). The SDN in the male rat is 3-8 times larger than in the female rat, due to differences in perinatal steroid levels (Jacobson et al., 1980). The SDN is involved in aspects of male sexual behavior (i.e., mounting, intromission, and ejaculation). Mounting behavior is not only affected by SDN lesions in male rats, but also in female rats (De Jonge et al., 1989; Turkenburg et al., 1988). The SDN in the young adult human brain is twice as large in males as in females and contains twice as many cells (Swaab and Fliers, 1985; Fig. 1). The SDN is identical to the "intermediate nucleus" described by Braak and Braak (1987). Sexual dimorphism in the human brain is not present at birth (Fig. 1). At that moment, the SDN contains only some $20 \%$ of the cell number found around 2-4 years of age. From birth up to this age, cell numbers increase rapidly in a similar way in both sexes. A sex difference does not occur until about the fourth year postnatally, when cell numbers start to decrease in girls, whereas the cell numbers in the SDN remain stable until approximately 50 years of age in males (Swaab and Hofman, 1988). Cell numbers in the male SDN decrease sharply after this age and in females a second phase of marked cell loss sets in after the age of 80 (Fig. 1; Hofman and Swaab, 1989). The sharp decrease in cell numbers in this nucleus later in life might be related to the dramatic hormonal changes which accompany both male and female senescence (Hofman and Swaab, 1989), and to the decrease in male sexual activity. It is not clear whether the hormonal changes would be cause or effect of the observed cell loss in this nucleus. Cell numbers in the SDN of Alzheimer's disease patients were found to be within the normal range for age and sex so that this condition does not seem to affect the SDN in any specific way (Swaab and Hofman, 1988).

\section{Nucleus Tuberalis Lateralis}

The lateral tuberal nucleus (NTL) is present in man and higher primates. In adulthood it contains some 60000 neurons whereas in Huntington's disease this number may be reduced to about 10000 (Kremer et al., 1990) 


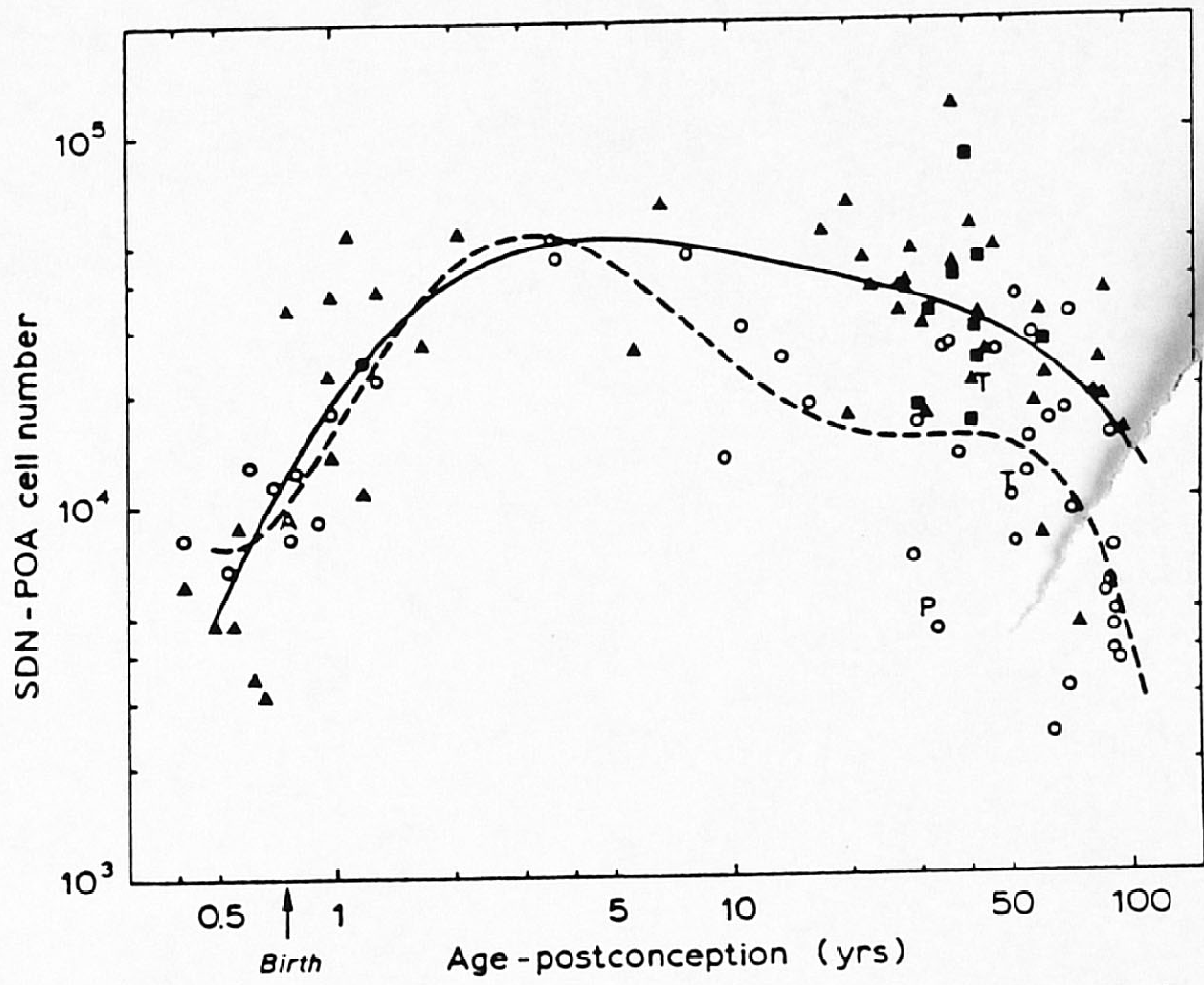

Figure 1. Development and sexual differentiation of the human sexually dimorphic nucleus (SDN) of the preoptic area of the hypothalamus. Log-log scale. Note that at the moment of birth the SCN is equally small in boys $(\triangle)$ and girls (O) and contains only about $22 \%$ of the cell number found at 2-4 years of age. The SDN cell number of a female neonate with a pituitary aplasia (A) is fully within the range of other neonates. Cell numbers reach a peak value around $2-4$ years postnatally, after which a sexual differentiation occurs in the SDN due to a decrease in cell number in the SDN of women, whereas the cell number in men remains approximately unchanged up to the age of 50 . Note that in men the reduction in cell number in senescence is less dramatic. The largest discrepancy in cell number between men and women is found around 30 years and in people older than 80, whereas the sexual dimorphism in the SDN cell number is least around the age of 60 . The SDN cell number in homosexual men ( $\square$ ) does not differ from that in the male reference group. The cell number of the SCN of two male-to-female transsexuals $(T)$ is within the female range, whereas the SDN of a woman with a Prader-Willi syndrome $(\mathrm{P})$ is small. The curves are quintic polynomial functions fitted to the original data for males (solid line) and females (dashed line), with Fs $[5,49]=10.05, \mathrm{P}<0.001$, and Fs $[5,39]=7.32, \mathrm{P}<0.001$, respectively). From: Swaab and Hofman, 1988 (with permission).

depending on the age at onset of the disease and age at death. Pathological changes in the NTL have also been described in depression (Horn et al., 1988), Kallman's syndrome (Kovacs and Sheehan, 1982) and dementia with intracranial argyrophilic grains and silver-staining coiled bodies, 
containing straight filaments (Braak and Braak, 1989). In Alzheimer's disease, the number of NTL neurons did not differ from controls. The number of plaques in this nucleus was low, and they were exclusively of the amorphous type. Neurofibrillary tangles were rare in conventional silver stainings. Yet, immunocytochemical staining using the monoclonal antibody Alz-50 showed such an abundant reactivity of both perikarya and neurites that the NTL of Alzheimer's disease patients could even be recognized by the naked eye (Kremer et al., 1991). The NTL seems to represent a brain area in which Alzheimer's disease affects the neurons in a limited way, without further progress to the classical changes of silver staining of tangles and neuronal loss. Lesions in the lateral hypothalamus are known to be associated with a catabolic state. In Huntington's and in Alzheimer's diseases dementia is combined with severe weight loss associated with normal or even increased food intake, as is the case in the condition described by Braak and Braak (1989). Because NTL pathology is accompanied by cachexia also in this condition (H. Braak, personal communication) the NTL is hypothesized to play a role in feeding behavior and metabolism.

\section{Suprachiasmatic Nucleus}

The suprachiasmatic nucleus $(\mathrm{SCN})$ is considered to be the major circadian pacemaker of the mammalian brain, coordinating hormonal and behavioral circadian rhythms (Rusak and Zucker, 1979). At birth the SCN contains some $13 \%$ of the vasopressin-expressing neurons and $20 \%$ of the total cell number found in adulthood (Fig. 2). Subsequently, cell numbers rise to maximum values around 1-2 years postnatally, after which they decrease gradually to some 50\% in adulthood (Swaab et al., 1990). Agerelated changes in circadian rhythms have been reported in man as well as in nonhuman species (Van Gool and Mirmiran, 1986). A fragmentation of sleep-wake patterns occurs in senescence, a phenomenon that is even more pronounced in Alzheimer's disease (Mirmiran et al., 1988; Witting et al., 1990). In Alzheimer's disease the disruptions of the circadian rhythms are often so severe that they are even thought to contribute to the mental decline (Fekete et al., 1985). In addition, sleep disturbances often lead to hospital admission of the elderly (Sanford, 1975). Total SCN cell numbers and numbers of vasopressin-expressing neurons were, therefore, determined during aging and in Alzheimer's disease. A marked decrease was found in SCN cell number in subjects of 80-100 years of age, while in Alzheimer's disease these changes were even more dramatic (Swaab 
et al., $1985 ; 1987)$. In this respect it is important to note that both the retina and the optic nerve, which provide direct and indirect input to the SCN, show degenerative changes in Alzheimer's disease (Hinton et al., 1986; Katz et al., 1989; Trick et al., 1989). In addition to degenerative changes, Alzheimer patients are generally exposed to less light than their age-matched controls (Campbell et al., 1988). As a result, both the inpurt of the visual system to the SCN and the SCN itself seem to be seriously affected in Alzheimer's disease. The contribution of each of these components to circadian disturbances has yet to be investigated.

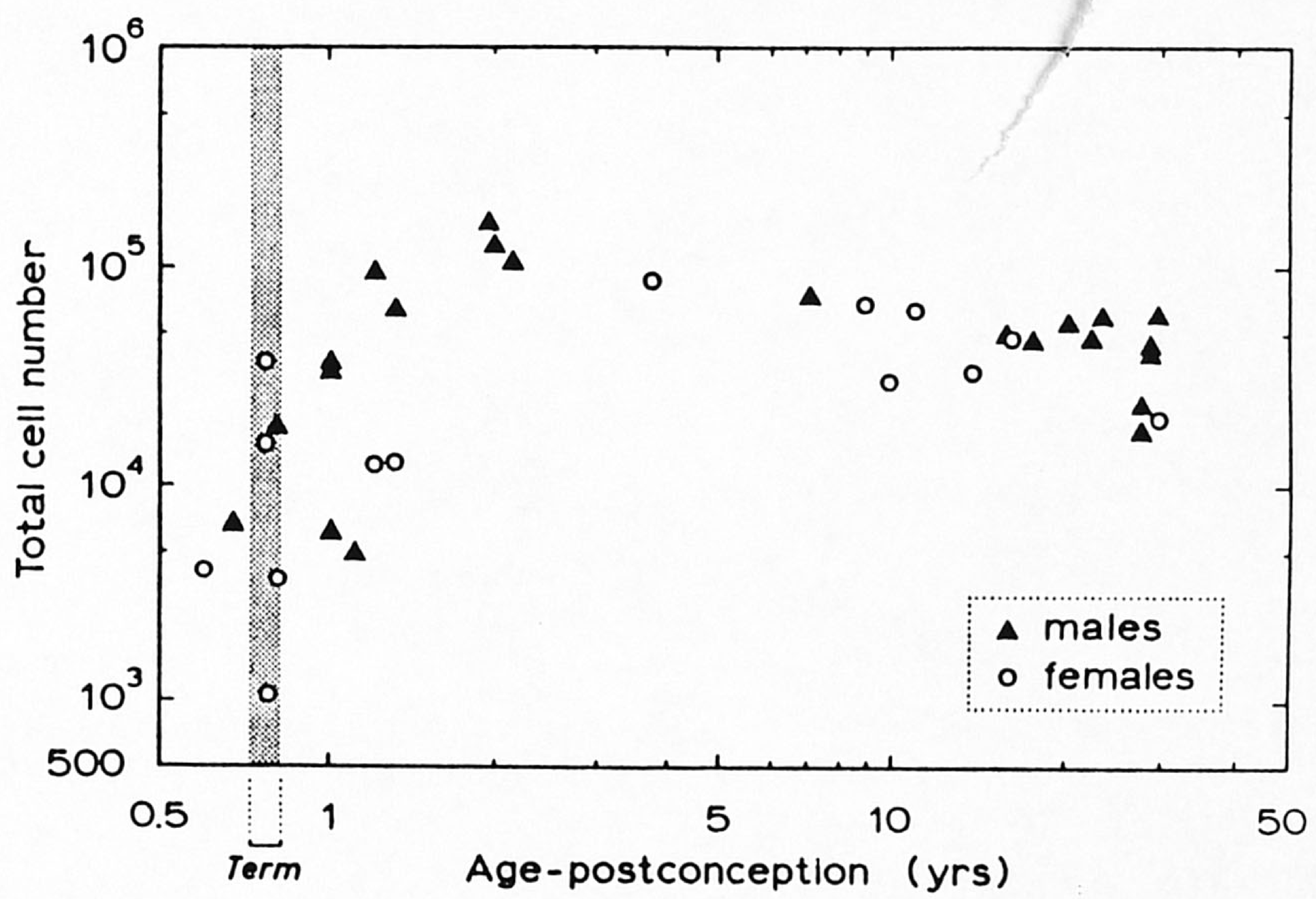

Figure 2. Development of the human suprachiasmatic nucleus (SCN) of the hypothalamus. Log-log scale. The period at term (38-42 weeks of gestation) is indicated by the vertical bar. Note that total cell number is low at the moment of birth (21\% of the cell number found in adulthood). There is no difference in the developmental course of the $\mathrm{SCN}$ in boys and girls. Cell numbers around 1-1.5 years postnatally are more than twice the adult cell numbers. After these high levels a decrease to adult total cell number is found. From Swaab et al., 1990, with permission.

In the SCN of the aged rat, the total cell number remained unaltered, but the number of vasopressin- and vasopressin-intestinal-peptide (VIP)expressing neurons in the SCN was significantly diminished (Chee et al., 1988; Roozendaal et al., 1987). These changes may be related to the diminished amplitude of circadian rhythms observed in aged rats (Van Gool and Mirmiran, 1983). Recent observations (Witting et al., in preparation) showed that by increasing the environmental light intensity, the 
circadian amplitude of sleep/wakefulness in old rats can be brought up to the level of young animals. This finding fits with the idea that activation might restore neuronal functions in aging (see below).

\section{Supraoptic and Paraventricular Nucleus}

The neurosecretory cells of the hypothalamic supraoptic and paraventricular nucleus (SON and PVN) produce the neuropeptides vasopressin and oxytocin, which are released into the blood circulation in the neurohypophysis. These neurons form a population of extremely stable cells. Neither in the course of normal aging nor in Alzheimer's disease patients were any significant loss in neurons or total cell number observed (Goudsmit et al., 1990). Various recent observations provide evidence for the hypothesis that activation of neurons may interfere with the process of aging, and thus prolong the life span of neurons or restore their function. This hypothesis is paraphrased as "use it or lose it." The SON and PVN neurons are not only metabolically highly active throughout life, but they are even additionally activated in senescence, as can be judged from the increase in the size of the vasopressin-containing perikarya (Fliers et al., 1985) and nucleoli (Hoogendijk et al., 1985), and the enhanced plasma levels of vasopressin (Frolkis et al., 1982) and neurophysins (Legros et al., 1980). Similar activation of vasopressin neurons was observed in the aged rat (Fliers and Swaab, 1983; Goudsmit et al., 1988) and is probably due to a loss of vasopressin receptors in the kidney during aging (Ravid et al., 1987). The hypothesis that the neurosecretory cell number is so stable because they are extra-activated needs to be tested experimentally, e.g., by long-term inhibition of these neurons during aging, in which case neuronal degeneration is expected to occur.

\section{Activation Restores Innervation}

An example of activation restoring a peptide system during aging was recently observed in the rat. Vasopressin innervation in the senescent male rat brain is particularly decreased in those regions where the fiber density in young adult males was shown to be dependent upon plasma levels of sex steroids (Fliers et al., 1985). Plasma testosterone levels and testicular weight decrease progressively with age in the rat (Ravid et al., 1987). However, when old rats were treated with testosterone for one month, the vasopressin innervation in the rat brain was restored. The vasopressin fiber system responding to the testosterone treatment 
(Goudsmit et al., 1988) originates from the bed nucleus of the stria terminales (BST) and medial amygdala, where testosterone seems to stimulate vasopressin synthesis. In castrated male rats, in which axonal transport was blocked by means of colchicine, testosterone increased the number of BST neurons expressing vasopressin (Van Leeuwen et al., 1985). Moreover, vasopressin-producing neurons in the BST and amygdala were shown to contain steroid hormone receptors (Axelson and Van Leeuwen, 1990). Thus, the increased vasopressin staining in aged animals following testosterone treatment demonstrates how activation of the synthetic activity of peptidergic neurons (i.e., BST neurons) may reverse the agerelated changes in their termination.

\section{Summary and Conclusions}

The human hypothalamus contains several nuclei manifesting a wide variety of changes in aging and Alzheimer's disease that might be related to a particular symptomatology.

In the first place, the SDN shows a decreased cell number during prepubertal development leading to sexual dimorphism and, subsequently, a decrease in cell number in both sexes during normal aging. The latter change is possibly related to a decrease in sexual activity and changes in hormone levels. In Alzheimer's disease cell numbers decrease at a similar rate as in normal aging (Swaab and Hofman, 1988).

The NTL might be involved in feeding behavior and metabolism. It does not show any decrease in neuronal numbers in Alzheimer's disease. Yet, a very strong Alz-50 staining is present in the NTL of these patients that is based upon a dense network of dystrophic neurites and numerous stained perikarya. The NTL in Alzheimer's disease patients seems, therefore, to be in an early phase of the disease process. In addition, we may conclude that Alz-50 is not simply a marker for cell death.

The SCN coordinates circadian rhythms. Its cell number decreases $50 \%$ from 1-2 years postnatally to adulthood and, subsequently, during normal aging. In Alzheimer's disease, the decrease in cell number is even more pronounced. This pathology might be the neural basis for the nightly restlessness observed in Alzheimer's disease, whereas alterations in the visual system (previously discussed) might contribute to these functional disturbances. It seems worthwhile, therefore, to try and see whether stimulation of the visual pathways by light therapy might increase the amplitude of the circadian rhythms in Alzheimer patients in a similar way as it does in the aged rat. 
The cells of the SON and PVN are examples of neuron populations that seem to stay perfectly intact in aging and Alzheimer's disease. We hypothesize that this might be due to the activation of these endocrine cells during the aging process, a hypothesis that will be tested in animal experiments. We have already shown that neurons also may be activated in very old rats, if the right stimulus (e.g., testosterone for the BST) is offered.

For several reasons, the hypothalamus offers a unique brain structure for the study of basic questions on the changes in aging and Alzheimer's disease, since (1) its nuclei can be delineated, which enables determination of changes in cell numbers, (2) the various hypothalamic nuclei show a wide range of variations in aging and Alzheimer's disease, and (3) it becomes increasingly possible to relate the cell number and neuropathological changes in the different nuclei to functional changes, either in terms of behavior or in endocrine changes. Such studies might establish the beginning of a neglected topic in neuropathology, namely, the neuropathology of the human hypothalamus.

Acknowledgments. Brain material was obtained from the Netherlands Brain Bank, Amsterdam. The authors would like to express their thanks to Mr. B. Schillings for his secretarial help.

\section{References}

Axelson JF, Van Leeuwen FW (1990): Differential localization of estrogen receptors in various vasopressin synthesizing nuclei of the rat brain. $J$ Neuroendocr 2:209-216

Braak H, Braak E (1987): The hypothalamus of the human adult: chiasmatic region. Anat Embryol 176:315-330

Braak H, Braak E (1989): Cortical and subcortical argyrophylic grains characterize a disease associated with adult onset dementia. Neuropathol Appl Neurobiol 15:13-26

Campbell SS, Kripke DF, Gillin JC, Hrubovcak JC (1988): Exposure to light in healthy elderly subjects and Alzheimer patients. Physiol Behav 42:141-144

Chee CA, Roozendaal B, Swaab DF, Goudsmit E, Mirmiran M (1988): Vasoactive intestinal polypeptide neuron changes in the senile rat suprachiasmatic nucleus. Neurobiol Aging 9:307-312

De Jonge FH, Louwerse AL, Ooms MP, Evers P, Endert E, Van de Poll NE (1989): Lesions of the SDN-POA inhibit sexual behavior of male Wistar rats. Brain Res Bull 23:483-492

Fekete M, Van Ree JM, Niesink RJM, De Wied D (1985): Disruption of circadian rhythms induces retrograde amnesia. Physiol Béhav 34:883-887 
Fliers E, Swaab DF (1983): Activation of vasopressinergic and oxytocinergic neurons during aging in the Wistar rat. Peptides 4:165-170

Fliers E, De Vries GJ, Swaab DF (1985): Changes with aging in the vasopressin and oxytocin innervation of the rat brain. Brain Res 348:1-8

Frolkis VV, Golovchenko SF, Medved VI, Frolkis RA (1982): Vasopressin and cardiovascular system in aging. Gerontology 28:290-302

Gorski RA, Gordon JH, Shryne JE, Southam AM (1978): Evidence for a morphological sex difference within the medial preoptic area of the rat brain. Brain Res 148:333-346

Goudsmit E, Fliers E, Swaab DF (1988): Testosterone supplementation restores vasopressin innervation in the senescent rat brain. Brain Res 473:306-313

Goudsmit E, Swaab DF (1989): Neuroendocrine aspects of normal and pathological aging. In: Recent Advances in Basic and Clinical Neuroendocrinology, Casanueva FF, Dieguez C, eds. Amsterdam: Elsevier Science Publishers, pp. 369-382

Goudsmit E, Hofman MA, Fliers E, Swaab DF (1990): The supraoptic and paraventricular nuclei of the human hypothalamus in relation to sex, age and Alzheimer's disease. Neurobiol Aging, in press

Hinton DR, Sadun AA, Blanks JC, Miller CA (1986): Optic nerve degeneration in Alzheimer's disease. $N$ Engl J Med 315:485-487

Hofman MA, Swaab DF (1989): The sexually dimorphic nucleus of the preoptic area in the human brain: a comparative morphometric study. J Anat 164:55-72

Hoogendijk JE, Fliers E, Swaab DF, Verwer RWH (1985): Activation of vasopressin neurons in the human supraoptic and paraventricular nucleus in senescence and senile dementia. J Neurol Sci 69:291-299

Horn E, Lach B, Lapierre Y, Hrdina P (1988): Hypothalamic pathology in the neuroleptic malignant syndrome. Am J Psychiatry 145:617-620

Jacobson CD, Shryne JE, Shapiro F, Gorski RA (1980): Ontogeny of the sexually dimorphic nucleus of the preoptic area. J Comp Neurol 193:541-548

Katz B, Rimmer S, Iragui V, Katzman R (1989): Abnormal pattern electroretinogram in Alzheimer's disease: evidence for retinal ganglion cell degeneration? Ann Neurol 26:221-225

Kovacs K, Sheehan HL (1982): Pituitary changes in Kallman's syndrome. A histologic, immunocytologic, ultrastructural, and immunoelectron microscopic study. Fert Steril 37:83-89

Kremer HPH, Roos RAC, Dingjan G et al. (1901): Atrophy of the hypothalamic lateral tuberal nucleus in Huntington's disease. J Neuropathol Exp Neurol 49:371-382

Kremer HPH, Swaab DF, Bots G, Fisser B, Ravid R, Roos RAC (1991): The hypothalamic lateral tuberal nucleus in Alzheimer's disease Ann Neurol 29:274284

Legros JJ, Gilot P, Schmitz S, Bruwier M, Mantanus H, Timsit-Berthier M (1980): Neurohypophyseal peptides and cognitive function: a clinical approach. In: 
Progress in Psychoneuroendocrinology, Brambilla F, Racagni G, de Wied D, eds. Amsterdam: Elsevier Science Publishers, 325-337

Mirmiran M, Overdijk J, Witting W, Klop A, Swaab DF (1988): A simple method for recording and analysing circadian rhythms in man. J Neurosci Meth 25:209-214

Plum F, Van Uitert R (1978): Nonendocrine diseases and disorders of the hypothalamus. In: The Hypothalamus, Reichlin S, Baldessarini RJ, Martin JB, eds. New York: Raven Press, pp. 415-473

Ravid R, Fliers E, Swaab DF, Zurcher C (1987): Changes in vasopressin and testosterone in the senescent Brown-Norway (BN/BiRij) rat. Gerontol 33:8798

Roozendaal B, Van Gool WA, Swaab DF, Hoogendijk JE, Mirmiran M (1987): Changes in vasopressin cells of the rat suprachiasmatic nucleus with aging. Brain Res 409:259-264

Rusak B, Zucker I (1979): Neural regulation of circadian rhythms. Physiol Rev 59:449-526

Sanford JRA (1975): Tolerance of debility in elderly dependents by supporters at home: its significance for hospital practice. Br Med J 3:471-473

Swaab DF, Fliers E (1985): A sexually dimorphic nucleus in the human brain. Science 224:314-318

Swaab DF, Fliers E, Partiman TS (1985): The suprachiasmatic nucleus of the human brain in relation to sex, age and senile dementia. Brain Res 342:3744

Swaab DF, Roozendaal B, Ravid R, Velis DN, Gooren L, Williams RS (1987): Suprachiasmatic nucleus in aging, Alzheimer's disease, transsexuality and Prader-Willi syndrome. In: Progress in Brain Research, Vol. 72, Amsterdam: Elsevier Science Publishers, pp. 301-310

Swaab DF, Hofman MA (1988): Sexual differentiation of the human hypothalamus: ontogeny of the sexually dimorphic nucleus of the preoptic area. Dev Brain Res 44:314-318

Swaab DF, Hofman MA, Honnebier MBOM (1990): Development of vasopressin neurons in the human suprachiasmatic nucleus in relation to birth. Dev Brain Res 52:289-293

Trick GL, Barris MC, Bickler-Bluth M (1989): Abnormal pattern electroretinograms in patients with senile dementia of the Alzheimer type. Ann Neurol 26:226-231

Turkenburg JL, Swaab DF, Endert E, Louwerse AL, Van de Poll NE (1988): Effects of lesions of the sexually dimorphic nucleus on sexual behavior of testosterone-treated female Wistar rats. Brain Res Bull 21:215-224

Van Gool WA, Mirmiran M (1983): Age-related changes in sleep pattern of male adult rats. Brain Res 279:394-398

Van Gool WA, Mirmiran M (1986): Aging and circadian rhythms. In: Progress in Brain Research, Vol. 70, Aging of the Brain and Alzheimer's Disease, Swaab DF et al., eds. Amsterdam: Elsevier Science Publishers, pp. 255-279 
Van Leeuwen FW, Caffe AR, De Vries GJ (1985): Vasopressin cells in the bed nucleus of the stria terminalis of the rat: sex differences and the influence of androgens. Brain Res 325:391-394

Witting W, Kwa IH, Eikelenboom P, Mirmiran M, Swaab DF (1990): Alterations in the circadian rest-activity rhythm in aging and Alzheimer's disease. Biol Psychiatry 27:563-572 